\title{
Un-diagnosing persistent adult asthma
}

\author{
To the Editor:
}

The diagnosis of asthma is usually based on typical symptoms, family history, audible wheeze, peak flow, spirometry, possibly in conjunction with atopy and blood eosinophilia, as well as response to treatment. In cases for which the diagnosis is less clear-cut, other tests may be required, including impulse oscillometry (IOS), exhaled nitric oxide fraction (FeNO) and bronchial challenge testing (figure 1).

A common pattern in our asthma clinic would be a nonsmoking patient presenting to primary care with an episode of viral-associated persistent cough and wheeze, initially unresponsive to salbutamol and antibiotics, with a normal chest radiograph, negative sputum culture and normal peak flow, with or without normal spirometry. Such cases might then be given empirical treatment with inhaled corticosteroids (ICS), which might be continued over the longer term, especially if symptoms linger before being resolved. This also assumes that an alternative diagnosis has already been pursued in patients with persistent cough.

There is a psychological burden to an individual being diagnosed with asthma, in addition to the ongoing costs of treatment, along with the potential for ICS-related adverse effects. Once patients have been told that they have asthma and are administered maintenance therapy, it might be difficult to persuade those patients that either the initial diagnosis was incorrect or an intermittent episode of asthma has been subsequently resolved.

Diurnal variability on serial peak flow recordings could be a useful indicator of asthma, but it requires a motivated patient to properly perform and record accurate readings. Reversibility of spirometry to inhaled salbutamol ( $\geqslant 15 \%$ and $\geqslant 200 \mathrm{~mL}$ increase in FEV1) is only useful in patients who have impaired FEV 1 $<80 \%$ predicted, when there is potential room for bronchodilator response. For patients with a preserved FEV $1>80 \%$ predicted, or for patients who cannot perform adequate spirometry, it would be useful to consider using IOS, which requires less cooperation, as it is an effort-independent test that is carried out during normal tidal breathing [1]. A diagnosis of asthma could be supported by the presence of heterogeneity of airway resistance as the difference between $5 \mathrm{~Hz}$ and $20 \mathrm{~Hz}\left(\mathrm{R} 5-\mathrm{R} 20>0.07 \mathrm{kPa} \cdot \mathrm{L}^{-1} \cdot \mathrm{s}^{-1}\right)$ and salbutamol reversibility $\geqslant 40 \%[2,3]$.

One of the hallmarks of asthmatic inflammation is the presence of underlying airway hyper-responsiveness (AHR), as measured by bronchial challenge testing, using either direct (methacholine or histamine) or indirect (mannitol or adenosine monophosphate) acting stimuli [4]. Ideally, such a challenge test should be performed after having first stopped ICS for at least 2 weeks, in order to avoid the possibility of a false negative result. Our pragmatic regimen is to half the dose of ICS every week, until a $200 \mu \mathrm{g}$ beclometasone equivalent dose is achieved, whereupon it can be stopped, followed by repeat lung function, and if required, a challenge test 2 weeks later. The worsening of symptoms in association with obstructive lung function at this visit upon stopping ICS might be diagnostic in itself and obviate the need to perform challenge testing.

The dose-related suppressive effects of ICS on AHR are more pronounced for indirect- than direct-acting challenges $[5,6]$. Hence, if a challenge test is to be performed while ICS is still being administered, either methacholine or histamine should be used instead of mannitol. The American Thoracic Society advocates a cut-off value for methacholine challenge as the provocative concentration to produce a $20 \%$ fall in FEV 1 ( $\mathrm{PC} 20)$ of $\leqslant 4 \mathrm{mg} \cdot \mathrm{mL}^{-1}$ being indicative of positive AHR, whereas a cut off $>4 \leqslant 8 \mathrm{mg} \cdot \mathrm{mL}^{-1}$ is considered borderline [7]. However, the guidelines do not stipulate whether these PC20 cut-offs refer to patients who are either on or off ICS therapy. Others and we recommend a pragmatic cut-off value of PC20 $\leqslant 8 \mathrm{mg} \cdot \mathrm{mL}^{-1}$ for direct challenge $[8,9]$. We also advocate measuring FeNO when patients are off ICS. The reason for stopping treatment is that FeNO is maximally suppressed by low-dose ICS after 1-2 weeks,

@ERSpublications

A pragmatic process should be considered in patients with a questionable asthma diagnosis http://ow.ly/VRNr30fwzgs

Cite this article as: Lipworth BJ, Jabbal S. Un-diagnosing persistent adult asthma. Eur Respir J 2017; 50: 1701433 [https://doi.org/10.1183/13993003.01433-2017]. 


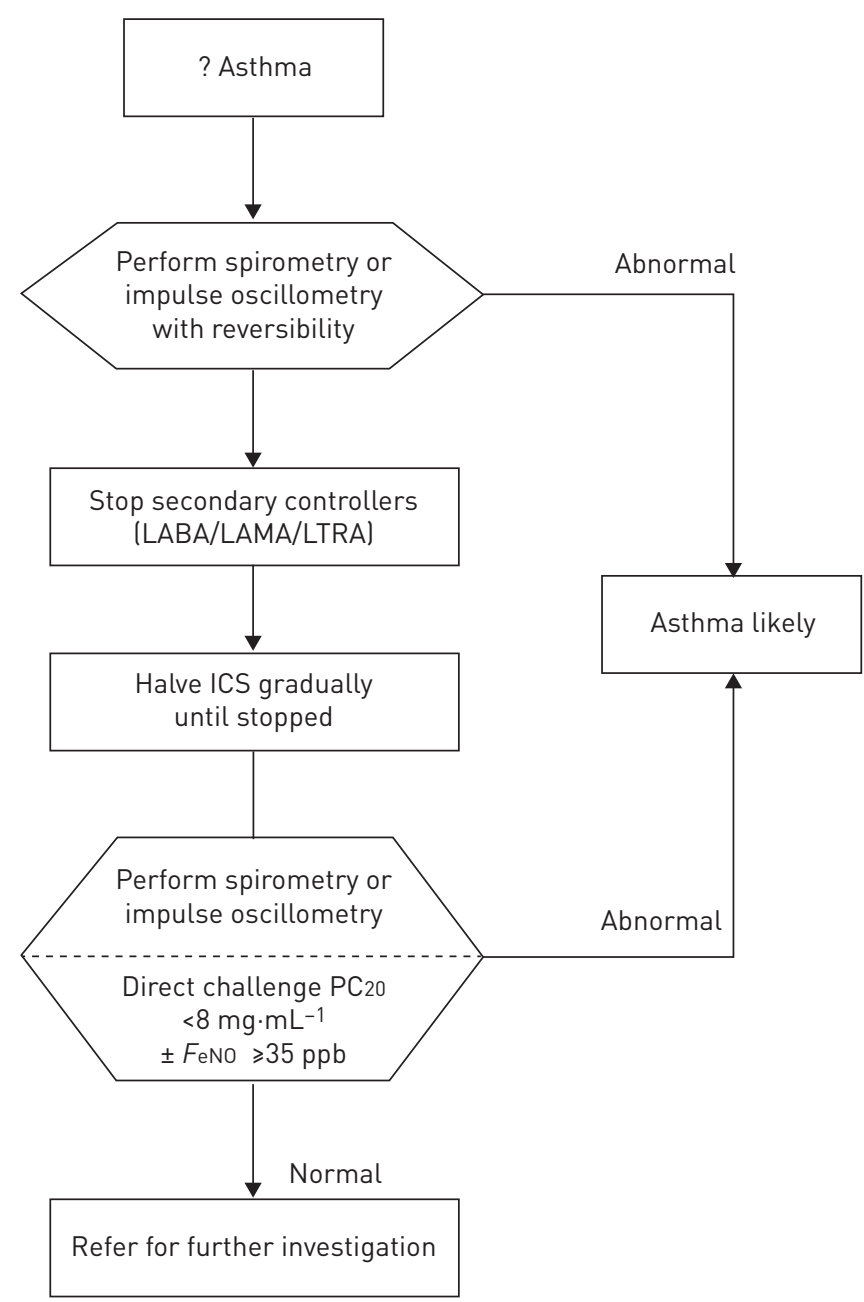

FIGURE 1 Flow chart for decision-making in difficult cases for which there might be uncertainty about the diagnosis of persistent adult asthma. LABA: long-acting $\beta$-agonist; LAMA: long-acting muscarinic antagonists; LTRA: leukotriene receptor antagonist; ICS: inhaled corticosteroid; PC20: provocative concentration causing a $20 \%$ fall in forced expiratory volume in $1 \mathrm{~s}$; FenO: exhaled nitric oxide fraction; ppb: parts per billion.

whereas values return to baseline after 1 week of ICS washout [10]. The ICS naïve patients with positive AHR (PC20 $\leqslant 8 \mathrm{mg} \cdot \mathrm{mL}^{-1}$ ) also have higher FeNO levels than those who are AHR negative [11]. In this regard, an elevated FeNO $\geqslant 35$ parts per billion [12] is highly predictive of persistent asthma for a patient who is not currently using ICS.

Prior to challenge in patients taking combination inhalers, the long-acting $\beta$-agonist (LABA) moiety should be stopped for 1 week while converting to ICS alone, followed by tapering. The additional effect of the LABA and leukotriene receptor antagonist (LTRA) on AHR amounts to less than one doubling dilution $[13,14]$, so that 1 week off such therapy should be sufficient washout in most cases. There is uncertainty about the protective effects of anticholinergics on AHR [15-17]. Long-acting muscarinic antagonists should be the first drugs withdrawn for 1 week [18], prior to stopping LABA, as part of sequential step-down therapy.

In a real-life study of community diagnosed asthma patients, $30 \%$ were nonresponsive to both methacholine and mannitol challenges, for whom the median beclometasone equivalent dose was $1000 \mu \mathrm{g}$, $68 \%$ were receiving LABA and 19\%, LTRA [9]. In comparison to the $70 \%$ who were responders to the challenge, significant differences were noted in the nonresponder mean values of FEV1 (88\% versus 100\%), mean FeNO (26 versus 16 parts per billion), asthma control questionnaire score (1.07 versus 0.55$)$ and skin prick positive response (79\% versus 50\%). A Canadian study found that $28 \%$ of patients with a physician-based diagnosis, who showed no evidence of asthma when their treatment was tapered and evaluated using direct challenge testing, yielded an estimated cost saving of $£ 2100$ for each un-diagnosed patient [19]. In another multicentre study in Canada using a similar protocol, current asthma was ruled 
out in $33 \%$ of cases, and after a further 12-month follow-up, $29 \%$ continued to show no evidence of asthma [8].

Patients with a negative challenge test, along with normal FeNO and IOS results, who also have persistent symptoms after having stopped ICS, should then proceed to have further tests conducted. These tests should possibly include upper and lower airway endoscopy, high resolution computed tomography (CT) scans of the thorax and gas diffusion, in order to exclude possible alternative diagnoses, such as chronic rhino-sinusitis, lung cancer, bronchiectasis and pulmonary embolism.

Brian J. Lipworth and Sunny Jabbal (1)

Scottish Centre for Respiratory Research, Ninewells Hospital and Medical School, Dundee, UK.

Correspondence: Brian J. Lipworth, Scottish Centre for Respiratory Research, Ninewells Hospital and Medical School, University of Dundee, Dundee, DD1 9SY, UK. E-mail: b.j.lipworth@dundee.ac.uk

Received: July 152017 | Accepted after revision: Aug 162017

Conflict of interest: Disclosures can be found alongside this article at erj.ersjournals.com

\section{References}

1 Galant SP, Komarow HD, Shin HW, et al. The case for impulse oscillometry in the management of asthma in children and adults. Ann Allergy Asthma Immunol 2017; 118: 664-671.

2 Manoharan A, Anderson WJ, Lipworth J, et al. Small airway dysfunction is associated with poorer asthma control. Eur Respir J 2014; 44: 1353-1355.

3 Short PM, Anderson WJ, Manoharan A, et al. Usefulness of impulse oscillometry for the assessment of airway hyperresponsiveness in mild-to-moderate adult asthma. Ann Allergy Asthma Immunol 2015; 115: 17-20.

4 Chapman DG, Irvin CG. Mechanisms of airway hyper-responsiveness in asthma: the past, present and yet to come. Clin Exp Allergy 2015; 45: 706-719.

5 Wilson AM, Lipworth BJ. Dose response evaluation of the therapeutic index for inhaled budesonide in patients with mild to moderate asthma. Am J Med 2000; 108: 269-275.

6 Currie GP, Stenback S, Lipworth BJ. Effects of fluticasone $v s$. fluticasone/salmeterol on airway calibre and airway hyperresponsiveness in mild persistent asthma. Br J Clin Pharmacol 2003; 56: 11-17.

7 Crapo RO, Casaburi R, Coates AL, et al. Guidelines for methacholine and exercise challenge testing - 1999. This official statement of the American Thoracic Society was adopted by the ATS Board of Directors, July 1999. Am J Respir Crit Care Med 2000; 161: 309-329.

8 Aaron SD, Vandemheen KL, FitzGerald JM, et al. Reevaluation of diagnosis in adults with physician-diagnosed asthma. JAMA 2017; 317: 269-279.

9 Manoharan A, Lipworth BJ, Craig E, et al. The potential role of direct and indirect bronchial challenge testing to identify overtreatment of community managed asthma. Clin Exp Allergy 2014; 44: 1240-1245.

10 Anderson WJ, Short PM, Williamson PA, et al. Inhaled corticosteroid dose response using domiciliary exhaled nitric oxide in persistent asthma the FENotype trial. Chest 2012; 142: 1553-1561.

11 Dupont LJ, Rochette F, Demedts MG, et al. Exhaled nitric oxide correlates with airway hyperresponsiveness in steroid-naive patients with mild asthma. Am J Respir Crit Care Med 1998; 157: 894-898.

12 Dweik RA, Boggs PB, Erzurum SC, et al. An official ATS clinical practice guideline: interpretation of exhaled nitric oxide levels (FENO) for clinical applications. Am J Respir Crit Care Med 2011; 184: 602-615.

13 Currie GP, Jackson CM, Ogston SA, et al. Airway-stabilizing effect of long-acting beta2-agonists as add-on therapy to inhaled corticosteroids. QJM 2003; 96: 435-440.

14 Currie GP, Lipworth BJ. Bronchoprotective effects of leukotriene receptor antagonists in asthma: a meta-analysis. Chest 2002; 122: 146-150.

15 Jabbal S, Manoharan A, Lipworth BJ. Bronchoprotective tolerance with indacaterol is not modified by concomitant tiotropium in persistent asthma. Clin Exp Allergy 2017; 47: 1239-1245.

16 Britton J, Hanley SP, Garrett HV, et al. Dose related effects of salbutamol and ipratropium bromide on airway calibre and reactivity in subjects with asthma. Thorax 1988; 43: 300-305.

17 Thomson NC, O'Byrne P, Hargreave FE. Prolonged asthmatic responses to inhaled methacholine. J Allergy Clin Immunol 1983; 71: 357-362.

18 O'Connor BJ, Towse LJ, Barnes PJ. Prolonged effect of tiotropium bromide on methacholine-induced bronchoconstriction in asthma. Am J Respir Crit Care Med 1996; 154: 876-880.

19 Pakhale S, Sumner A, Coyle D, et al. (Correcting) misdiagnoses of asthma: a cost effectiveness analysis. BMC Pulm Med 2011; 11: 27. 